\title{
BIOMETRICS - MARKET SEGMENTS AND APPLICATIONS
}

\author{
Gregor Költzsch \\ University of Applied Sciences Stralsund, Fachhochschule Stralsund, Zur Schwedenschanze 15, \\ 18435 Stralsund, Germany. E-mail: Gregor.Koeltzsch@gmx.de
}

Received 17 May 2006; accepted 7 December 2006

\begin{abstract}
Biometric methods are concerned with the measurement and evaluation of human physiological or behavioral characteristics. During the last years, the economic relevance of the biometric industry and market has increased rapidly. Although public security projects have initiated the positive market development, future growth will be also generated by private sector demand such as secure and convenient banking, payment applications etc.

The deployment of biometrics to machine readable travel documents such as passports provides citizens with first experiences in biometric applications, thereby functioning as pioneer projects and market openers for other market segments. For example, biometric passports will redefine the border control process in the future, and in the midterm, aviation security is another market segment that will contribute to the growth. To prepare for this business, the industry must carefully analyze the market and meet the demand. This article assesses the economic relevance of biometrics and discusses selected market segments.
\end{abstract}

Keywords: Biometrics, biometric market, biometric industry, security systems, border control, aviation security.

\section{Biometrics and people}

The objective of the present article is to describe the economic relevance of biometric technologies and to provide an overview of market segments and business-oriented applications of biometric methods.

Although biometrics are a very young technology, they increasingly influence the security industry and markets. Since 11 September 2001 public security concerns have risen constantly, and the increase of international terrorism can be observed in a worldwide series of threats and attacks. To prevent and fight terrorism, governments and authorities seek to issue more secure identification documents, protect borders and monitor public places. This demand for enhanced public security is served by the security industry and the biometrics industry in particular.

However, biometric technologies will play a significant role in private sector markets and convenient driven applications as well.
What are biometrics? The term biometrics derives from the Greek words "bios" (life) and "metron" (measure). In a broader sense, biometrics can be defined as the measurement of body characteristics, in other words, biological statistics [1]. With this meaning this term has been used in medicine, biology, agriculture and pharmacy. Criminal prosecution, forensics and police records have used pictures, body height and finger prints for a long time [2].

However, the invention of automated technologies to measure and evaluate physical or behavioral characteristics of living organisms has given the word a second meaning. Research on computer-based, automated recognition of physiological and behavioral characteristics started in the 1960s, and the first commercial application was installed in 1968 [3]. In the present article, the term "biometric technologies" refers to automated methods of recognizing a person based on physiological or behavioral characteristics [4].

Automated systems based on biometrics to recognize persons enable fast, user-friendly and highly secure 
identification and verification processes. Among the most-used biometric technologies are facial, fingerprint, iris, signature and voice recognition [5].

Since biometric methods take advantage of mostly unchangeable characteristics, they are more reliable than other methods of authorization such as PIN codes and magnet stripe cards that are based on knowledge or possession. Moreover, biometric characteristics can neither be stolen nor transferred.

\section{Biometrics and business}

Biometric technologies are of particular business interest because they are widely applicable, connected to major political and security-related interests and have a strong interdependency with other security technologies.

Forecasting the international and national biometric markets turns out to be a difficult task, considering the high diversity of analysis results in international studies. However, all market studies show that the market has grown at an annual world market growth of 30 to $60 \%$ in the last few years [6]. As the market has grown bigger now, the annual growth rate will reduce to a level between 20 and $40 \%$. The following chart illustrates the market expectations to 2010 (Fig 1):

Over the last decade, worldwide biometric revenues have multiplied tenfold.

Biometric World Market Revenue 2007-2012

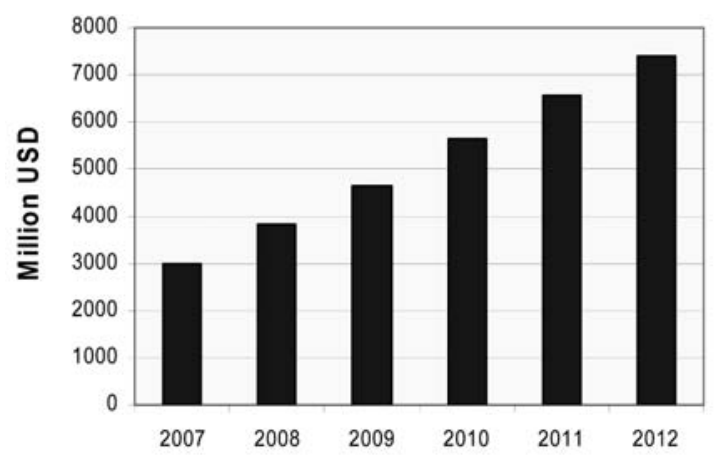

Fig 1. World Market Volume 2007-2012 [7]

\begin{tabular}{|c|c|}
\hline Year & Million • \\
\hline 2007 & 360.0 \\
\hline 2008 & 483.5 \\
\hline 2009 & 558.1 \\
\hline 2010 & 614.9 \\
\hline
\end{tabular}

Fig 2. European Market Volume 2007-2010 [8]
Following the world market, the European market is also growing rapidly (Fig 2).

In the long term the private sector demand could even exceed the demand in the public market segments, considering the high number and diversity of potential private industry customers and consumers.

Despite the impressive market figures we have to bear in mind that biometric products and solutions are usually part of overall systems and combined with other technologies that are necessary to exploit their capabilities. For example, storage and processing mediums such as data bases and smart cards are required to store the biometric data. Radio Frequency Identification (RFID) supports the growth of the biometric markets because it enables the contactless transfer of biometric data.

\section{Target market segments}

\subsection{Overview}

The biometric market segments range from sovereign applications such as identification documents to consumer applications, e.g. laptop access with fingerprint recognition. Depending on the market segment, the use of biometrics can be security-driven or convenience-driven. In real life, many applications will combine both. For example, the laptop user prevents the laptop from being used by others (security) but, simultaneously, avoids memorizing user name and password (convenience) [9].

Some of the most important future application fields may be (Fig 3) [10].

Each market segment must be analyzed in detail to learn how the demand is structured and how it can be served by the industry. Two market segments border control and aviation - will be taken as examples to illustrate how biometrics influence certain market segments.

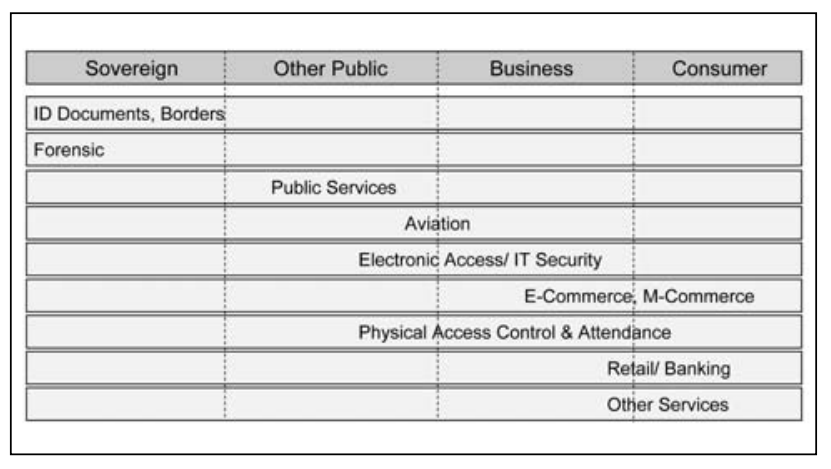

Fig 3. Market segments of biometrics 


\subsection{Market segment border control}

The international deployment of biometrics to machine readable travel documents enables new business for the biometric industry worldwide. Following the integration of biometric data into passports and, in the mid-term, ID cards, the use cases for these documents in practice will change as well. Since the electronic passport is the first internationally standardized travel document in which biometrics are integrated, those use cases that require passports will change the most. Primarily, this is border control. Border authorities want to know if the person at the border control point is actually the one he or she claims to be, and whether the passport is genuine or not. With the help of biometric methods, the identity of a person crossing the border can be verified by comparing an image captured in the very moment with the biometric data stored on the passport.

Second, authorities may run the captured data against data bases as far as this is permitted by national law. For example, these could be visa registers or crime records. But biometric border control is not only able to increase security but also convenience. Registered travelers whose biometric data is known by authorities will be processed faster than conventional travelers.

These new concepts require sophisticated process redesigns and initiate market segment growth for the security industry. Depending on the individual concept, control points have to be equipped with document readers, biometric sensors, IT networks, automated doors etc. Moreover, connection to national and international data bases must be established and secured. As soon as biometric technologies are introduced into a certain process step at the border, they will eventually change the border control process far more than one could originally think. Modern and innovative high technology approaches are crucial for border control. The combination of electronic passports including biometric features, appropriate control devices and integrated security systems will be an integral part of the border control segment.

It is a good chance for business to take advantage of this development, and governments may present their countries as modern and technology-oriented business locations.

In the European context, border protection becomes particularly important since the control points between the Schengen countries are not longer active. Therefore, the protection of every single control point at the EU border is vital for all member states. Any member state's security approach influences security all over the European Union. If terrorists, criminals or illegal immigrants cannot be stopped at the first point of entry, they have a free ride into the European Union.

Vice versa, border control is no longer only the responsibility of individual countries to protect their own citizens but implicates responsibility of the individual country towards all other member states. This responsibility will be demanded by the member states from each other and does include the new member states in Eastern Europe. As soon as Lithuania enters the Schengen area, the country will also have to assume this responsibility.

\subsection{Market segment aviation}

Aviation security will be among the market segments that profit the most from pioneer projects in the field of border security. Unlike land border control points, air border control points are not located at a country's geographical border but right at the airports. Therefore, border security at airports goes along with aviation security.

Airports are complex and vulnerable entities with a high passenger and goods flow. Airlines and airports have to show highest performance in short time spans. The situation is even more complex because at airports, public security interests are tied closely to private security interests and responsibilities. Considering the various security activities, sovereign and private responsibilities overlap at airports. Passengers on international, Non-Schengen departures run through a series of public and private security control points. For example, security requirements for passengers traveling to the United States have been increasing constantly. Moreover, public authorities such as border police often outsource responsibilities at airports to private companies.

Both public authorities (e.g., border police) and private actors (e.g., airport security personnel) must rely on each other and cannot be successful without each other. This makes the development of overall security concepts inevitable. Aviation security can only be maintained with a mix of activities by public and private parties. In the long term, governments, airlines and airports must provide a holistic security approach at air borders and airports to protect trade and international tourism.

But again, customer convenience is as important as security. All concepts must provide efficient, 
convenient and passenger-friendly approaches. This overall approach must focus on the passenger clearance process and include all process steps from checkin and security checks to boarding. Furthermore, the process must be interoperable for all involved airlines, airports and other participants. These requirements will support strong market segment growth because the security industry is needed to support authorities, airlines and airport operators with process redesign, equipment of airports and integration of processes.

Although this might represent a hard challenge considering the different interest groups and their responsibilities, it is supported by the success of biometric travel documents, particularly the passport. Once sovereign border control at airports has introduced processes based on electronic travel documents and biometrics, private sector applications in the civil aviation business will profit from these pioneer applications. Private parties such as airports and airlines are likely to redesign their processes alike, and establish related applications.

Biometric methods will not substitute holistic security and convenience concepts but may provide the technological basis for those concepts and process optimizations.

\section{Perspectives}

The first large-scale biometric projects in the public sector will initiate strong growth of the biometric markets and provide the chance to realize business opportunities.

Furthermore, these public projects will act as market openers and multiplicator projects for private sector projects. Particularly, it is expected that the worldwide introduction of electronic identification documents will support the market penetration of biometric technologies, particularly in the border control and aviation market segments.
However, the market for convenience driven applications will accelerate as well. Eventually, we will even see the market penetration of biometric methods in convenience-oriented consumer applications, such as payment in supermarkets, controlling of household appliances, ticketing etc.

These developments are a business opportunity that has to be taken by the industry in cooperation with academic research.

\section{References}

1. NOLDE, V. Grundlegende Aspekte biometrischer Verfahren. In Nolde, V.; Leger, L. (Eds.). Biometrische Verfahren. Fachverlag Deutscher Wirtschaftsdienst, Cologne, 2002, p. 20.

2. ALBRECHT, A.; PROBST, T. Bedeutung der politischen und rechtlichen Rahmenbedingungen für biometrische Identifikationssysteme. In Behrens, M.; Roth, R. (Publ.). Biometrische Identifikation; Grundlagen, Verfahren, Perspektiven. Verlag Vieweg, Braunschweig, Wiesbaden, 2001, p. 31.

3. AMBERG, M. et al. Biometrische Verfahren; Studie zum State of the Art. Friedrich-Alexander-University Erlangen-Nuremberg, Erlangen/ Nuremberg, 2003, p. 5.

4. European Biometric Forum. Biometrics Lexicon. Available from Internet: <http://www.eubiometricforum.com/ index.php?option $=$ content $\&$ task= view $\& i d=29 \&$ Itemid $=46>$ Download 08/05/2006.

5. BIOVISION Consortium. Roadmap for Biometrics in Europe to 2010. Roadmap to Successful Deployment from the User and System Integrator Perspective. Ipswich 2003, p. 19.

6. International Biometric Group. Biometric Market Report 20032007, New York, 2003, p. 2.

7. International Biometric Group (2006). Biometric Market Report 2007-2012, New York, 2006. http://www.biometricgroup. com/reports/public/market_report.html

8. European Biometric Portal. Biometrics in Europe; Trend Report June 2006. Brussels, 2006, p. 51.

9. BIOVISION Consortium. Roadmap for Biometrics in Europe to 2010. Roadmap to Successful Deployment from the User and System Integrator Perspective. Ipswich, 2003, p. 6.

10. For example, see Elsevier Science. The Biometric Industry Report, Kidlington, 2002, p. 8. 